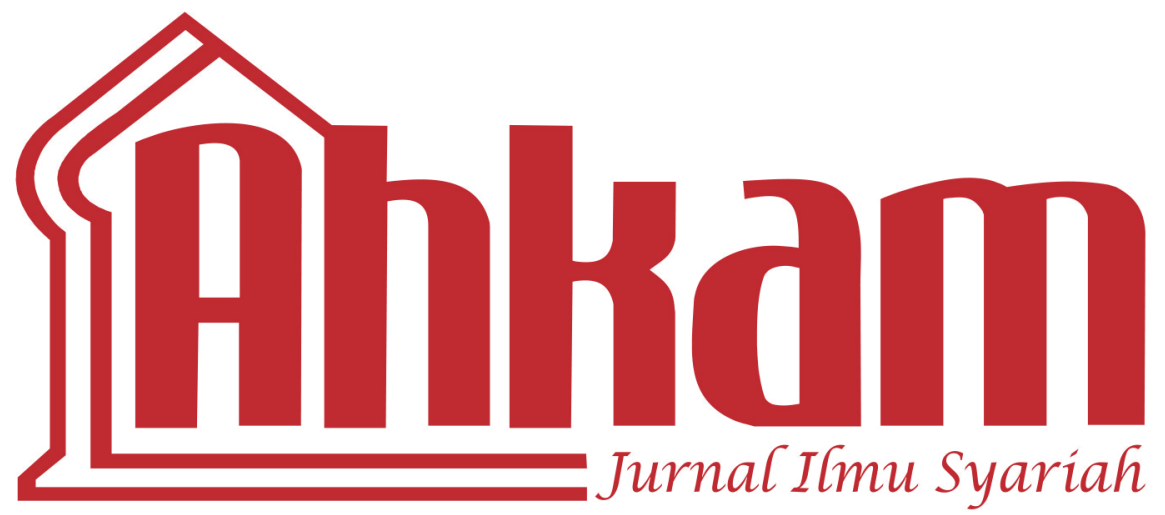

* Khamami Zada

The Rohingya's Muslim Asylum Seekers in Souteast Asia: From National to International Law Perspective

* Ilyya Muhsin

Endogamous Marriage of Jamaah Tarbiyah: A Sociological Study of The Jamaah Tarbiyah in Salatiga

* Muhammad Maksum

Building Flats Through Waqf Land: Legal Breakthrough and Obstacles

* Mustapa Khamal Rokan

Conceptualization of Economic Right for Small Traders at Traditional Market in Indonesia

* Fauzan \& Anis Fuadah Zuhri

Analysing the Essence of Fiqh Subjects in Curriculum 2013

* Amany Burhanuddin Lubis

Al-Shurūṭ wa al-Dawābiṭ al-Shar'iyyah li al-Ghidā al-Halāl: Khibrah Indūnisiyā 


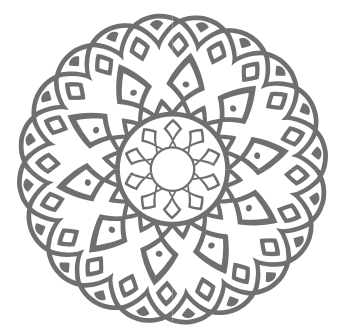

\title{
Kondisi Metereologi SaAt Pengamatan Hilal i Syawal I 438H di Indonesia: Upaya Peningkatan Kemampuan Pengamatan DAN ANALisis Data Hilal
}

Fuad Thohari, Achmad Sasmito, Andy ES, Jaya Murjaya, Rony Kurniawan

\begin{abstract}
Hilal observation done The Agency of Meteorology, Climatology, and Geophysics (BMKG) on June 24, 2017 at 17 Station Observations of BMKG for the determination of 1 Shawwal $1438 \mathrm{H}$ get the sighting the moon at Kupang Geophysical station. The result was still questioned by astronomers because in addition to their smaller size in terms of theory, it was also regarded as noise (disturbance). Re-observation at Kupang Geophysical Station with Vixen ED81S telescope and Canon 500D detector obtained data that the new moon position was in line with the calculation result (elongation $4^{\circ} 49^{\prime} 58$ ") with smaller diameter than the theoretical value (67\%). This article showed that the incident was suspected as a result of refraction so that the atmosphere seemed to function as a concave lens that resulted in the reduction of the object from its original size.
\end{abstract}

Keywords: ru’yat al-hilāl, hịisāb, 1 Shawwal 
Abstrak: Pengamatan hilal yang dilakukan BMKG pada 24 Juni 2017 di 17 Stasiun Pengamatan BMKG untuk penetapan 1 Syawal $1438 \mathrm{H}$ hanya diperoleh hasil penampakan bulan di stasiun Geofisika Kupang. Hasil tersebut diragukan para astronom karena di samping ukurannya yang lebih kecil dari segi teori, juga dianggap sebagai derau (gangguan). Pengamatan ulang di stasiun Geofisika Kupang dengan teleskop Vixen ED81S dan detektor Canon 500D justru diperoleh data bahwa posisi new moon sesuai dengan hasil perhitungan (elongation $4^{\circ} 49^{\prime} 58^{\prime}$ ) dengan diameter lebih kecil dari nilai teoritis $(67 \%)$. Artikel ini menunjukan bahwa kejadian tersebut diduga akibat refraksi sehingga atmosfer seakan-akan berfungsi sebagai lensa cekung yang mengakibatkan pengecilan benda dari ukuran aslinya.

Kata kunci: ru’yat al-hilāl, ḥisāb, 1 Syawal

$$
\begin{aligned}
& \text { ملخص: ان رؤية الهلال الذي قامت بها لجنة القومية لشؤون الأقمار والنجوم وجيوفيزيا } \\
& \text { قي rع يونيو r · V بمحطة اللجنة لاثبات أول شهر شوال فقط تم اطلاعها في محافظة } \\
& \text { كوفانج وهذه النتيجة مشكوك فيها بسبب مقدارها المصغر نظريا كما يعتبر عوارض } \\
& \text { وعوائق، فالرقابة وعملية الترصد بمحطة كوفانج بتقنية المكبرة ومرصاد من نوعية كينون رقم }
\end{aligned}
$$

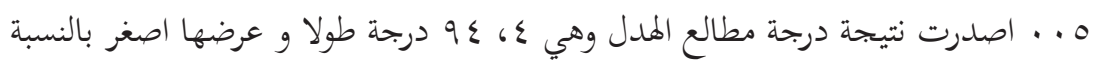

$$
\begin{aligned}
& \text { الى نتيجة نظرية (V7٪). وهذه المقالة تثبت بان المظاهر المذكورة وقعت بسبب التقطع }
\end{aligned}
$$

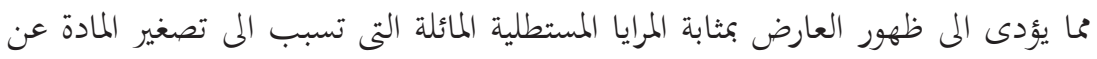

$$
\begin{aligned}
& \text { الأصل. } \\
& \text { الكلمات المفتاحية: رؤية الهلال، الحساب، ا شوال }
\end{aligned}
$$




\section{Pendahuluan}

Diskursus bulan Qamariyah, terutama penentuan awal Ramadhan, Syawal, dan Dzulhijjah merupakan persoalan klasik yang senantiasa aktual. Klasik karena persoalan ini semenjak masa awal Islam sudah mendapatkan perhatian dan pemikiran cukup serius dari pakar hukum Islam (Fuqaha') karena terkait erat dengan pelbagai ibadah dan melahirkan pendapat yang bervariasi. Disebut aktual karena hampir di setiap tahun terutama menjelang bulan Ramadhan, Syawal, dan Dzulhijjah persoalan ini selalu muncul dan mengundang polemik sehingga nyaris mengancam pilar kesatuan dan persatuan umat Islam (Fuad Thohari' 2012: 39-50). Selama sistem penanggalan Islam yang berhubungan dengan waktu ibadah dan disepakati dunia Internasional belum ada, pembicaraan mengenai penetapan awal bulan Islam (Qamariah) terus akan mengemuka. Diskursus ini, biasanya terfokus pada penentuan awal Ramadhan, Syawal, dan Dzulhijjah. Dalam ke tiga bulan tersebut, terdapat jadual ibadah umat Islam di seluruh dunia. Kondisi ini terkadang memicu beragamnya pelaksanakan awal Ramadhan, hari Raya dan Puasa Arafah (bagi umat Islam yang tidak Haji) yang dalam prakteknya menggunakan kalender bulan Qamariah berdasarkan penampakan hilal (bulan sabit pertama) sesaat matahari terbenam (Moedji Raharto 1997).

Menurut sebagain ahli Astronomi, kondisi geografis Indonesia relatif sulit dilakukan pengamatan hilal akibat proses fisis dan dinamis yang menyertai, di mana secara garis besar berdasarkan data klimatologi, Indonesia memiliki tiga (3) tipe iklim. Selain itu, secara umum, wilayah Indonesia dapat dikatakan banyak curah hujan sepajang tahun. Hal ini sekaligus menggambarkan bahwa awan atau kandungan uap air di udara relatif banyak, yang ditengarai menyebabkan kelembapan udara (RH) relatif tinggi sepanjang tahun. Keadaan inilah yang menyulitkan pengamatan hilal di Indonesia. Hasil pengamatan hilal yang dilakukan pada tanggal 24 Juni 2017 pukul 17:43 di stasiun Geofisika Kupang berhasil diperoleh gambar bulan baru (new moon) 1 Syawal $1438 \mathrm{H}$. Namun penampakan bulan tersebut diragukan para ahli astronomis karena ukuran penampakan bulan (hilal) lebih kecil dari segi teoritis dan penampakan tersebut dianggap sebagai derau (gangguan).

Artikel ini akan membahas tentang keberhasilan pengamatan hilal yang dilakukan pada tanggal 24 Juni 2017 pukul 17.43 di stasiun 
Geofisika, Kupang yang sempat diragukan para astronom karena ukuran penampakan (hilal) bulan lebih kecil dari segi teoritis. Selain itu artikel ini juga akan mengungkap berbagai metode dalam menetapkan penentuan awal Ramadhan, Syawal, dan Dzulhijjah serta problematika penyeragamannya.

\section{Paradigma Metodologis}

Data historis mengenai penetapan awal Ramadhan-sebagaimana diungkap dalam beberapa riwayat hadis-diilustrasikan begitu sederhana sesuai kondisi riil masyarakat Arab ketika itu yang tidak banyak mengerti tentang ilmu Astronomi dan Matematika dan bahkan mayoritas buta huruf. Rosulullah Saw telah membuat pedoman bagi umat Islam di Madinah pada tahun ke-2 Hijriah dan seterusnya, tentang cara memulai dan mengakhiri puasa Ramadhan yang dilanjutkan dengan hari Raya. Karena umur bulan Qamariah itu 29 atau 30 hari, penentuannya berdasarkan: pertama, kriteria visibilitas hilal sebagaimana hadis riwayat Imam Bukhāri (Muhammad bin Isma’il Al-Bukhāri 1987):

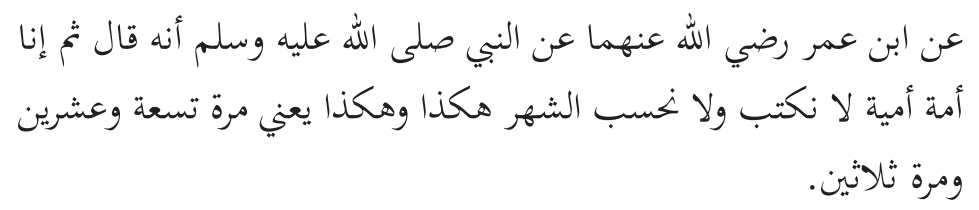

Kedua, dengan menggenapkan umur bulan Shaban atau Ramadan menjadi 30 hari apabila hilal tidak bisa diru'yat sebagaimana hadis riwayat Imam Muslim (Muslim bin Hajjaj Al-Nisabury, tt):

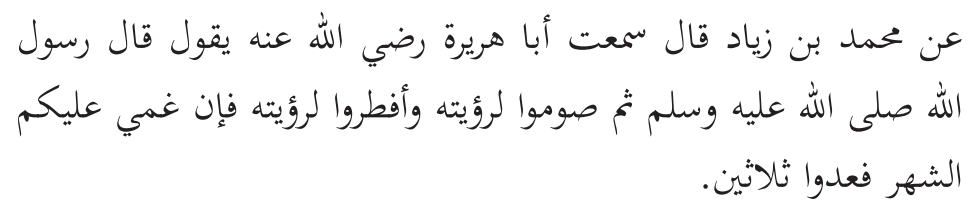

Hal ini berarti, Nabi Muhammad Saw tidak pernah menetapkan awal Ramad\{an dan 'Idul Fitri jauh sebelum waktunya. Prosedur penetapannya diputuskan setelah menerima berita rujyat. Bahkanmenurut Ibn Abbas-RasulullahSaw pernah memulai puasa Ramadhan hanya karena informasi seorang baduwi setelah disumpah sebagiaman hadisi diriwayatkan Imam dan Imam Hakìm (Muhammad Bin 'Abdullah Al-Hakim Al-Nisabury 1990): 


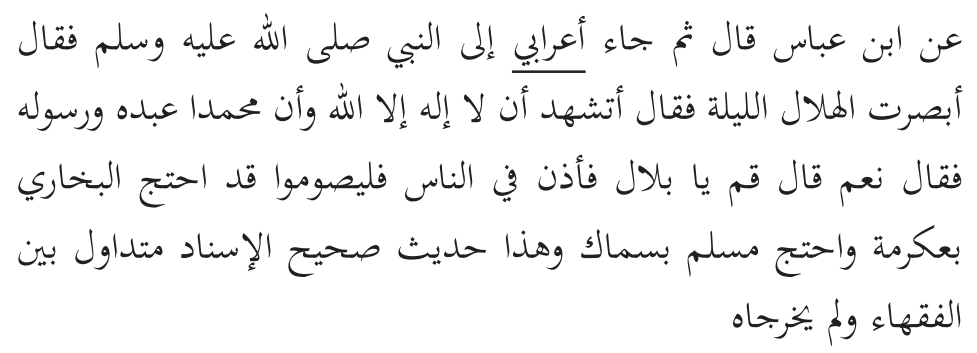

Beberapa ayat Alquran menyatakan, peredaran bulan dan matahari bisa dijadikan pedoman untuk menentukan awal bulan Qamariah. Dalam perkembangannya, Fuqāha' berbeda pendapat dalam menafsirkan ayat tersebut dikaitkan dengan teks hadith, laju sains dan teknologi, serta kondisi riil masyarakat di sekitarnya (Q.s. al-An'am (6): 96, Yasin (36): 39 dan Q.s. al-Baqarah (2): 187,189)

Silang pendapat prosedur penetapan awal Ramadhan dan hari Raya itu bermuara pada tiga paradigma metodologis antara lain: pertama, prosedur penentuan awal Ramadhan dan hari Raya cukup menggunakan rukyat, kedua, penentuan awal Ramaḍan dan hari Raya cukup dengan Hisab Astronomi dan ketiga, penentuan awal Ramaḍan dan hari Raya berdasarkan ru'yat yang didukung hisab Astronomi, dan hisāb Astronomi yang didukung ru'yat. Tiga paradigma metodologis tersebut dijumpai di Indonesia dan beberapa negara tetangga seperti: metode ruyat dipakai oleh NU dan Brunei Darussalam, metode Hisab Astronomi dipakai Muhammadiyah, Persis, dan Singapura dan perpaduan metode ru'yat dan metode Hisab Astronomi digunakan oleh MUI, Malaysia dan Kementerian Agama Republik Indonesia.

\section{Kendala Penyatuan Matla' Global}

Sampai saat ini, penetapan 1 Syawal antar negara berbeda-beda meskipun berdekatan, karena kebijakan penetapan tanggal 1 Syawal berada di tangan otoritas pejabat yang berwenang. Di Indonesia misalnya, kewenangan tersebut dimiliki oleh Menteri Agama Kementerian Agama Republik Indonesia setelah mendengar laporan-laporan masyarakatdi lapangan melalui Sidang Isbat. Secara historis, pengamatan hilal dapat dibaca dari hadis Nabi Saw: "Apabila seseorang telah melihat bulan baru, Nabi saw menyuruh para Sahabat membatalkan puasa dan sekaigus ditetapan 1 Syawal sebagai hari Raya Idul Fitri". Berdasarkan contoh pengalaman Nabi Saw tersebut, ada usulan sementara ahli seperti "Apabila 
seseorang di permukaan bumi manapun berada melihat bulan baru (hilal) 1 Syawal, sebaiknya diikuti umat Islam di seluruh dunia". Alasannya, apabila hari Raya dapat dilakukan secara serentak di seluruh dunia, akan meningkatkan syi'ar dan persatuan di kalangan umat Islam.

Pendapat yang bermuara pada upaya penyeragaman tanggal 1 Syawal dan Dzulhijah, tentu akan dihadapkan pada penolakan, karena Syawal dan Dzulhijah, lebih banyak terkait pelaksakan solat 'Idul Fiṭri dan 'Idul Adḥa, di mana waktu pelaksanannya tidak mungkin bisa disamakan karena perbedaan matla. Berbeda misalnya dengan upaya penyeragaman pelaksanakan awal puasa Ramaḍan di seluruh dunia.

Gagasan penyeragaman tanggal 1 Syawal dan Dzulhijah ini secara teoritis amat baik (Moh. Rodhi Sholeh 1992). Tetapi bila dicermati lebih jauh, ternyata secara substansial akan terbentur pada tiga kendala sebagai berikut: pertama, pengikut prosedural ru'yat atau istikmāl dalam menetapkan awal Ramaḍan dan hari Raya merasa yakin sudah benar menjalankan syari'at Islam. Ru'yat atau istikmäl merupakan satu-satunya pedoman yang diajarkan Rasulullah Saw. Konsekuensinya, keyakinannya tidak dapat dirubah agar mengikuti dasar Hisab Astronomi. Kedua, kendala internal ilmu Hisab Astronomi. Menurut data historis, disiplin ilmu ini sudah dikenal lebih dari seribu tahun lalu sebelum Nabi Isa lahir. Ilmu ini dicangkok dari India, Yunani, Cina, dan Mesir. Penulisannya dimulai sejak buku Sidharta (berbahasa India) diterjemahkan oleh Al-Fazari ke bahasa Arab di Baghdad pada tahun 771 M. Selanjutnya dilakukan penterjemahan dari daftar Pahlevi yang disusun sejak periode Sasania. Setelah itu, barulah diterjemahkan buku Yunani Almagest karangan Ptolomeus (Musyrifah Sunanto 1991: 61). Pada akhirnya, tabel ilmu Hisāb ini jika dikumpulkan dari dulu sampai sekarang, jumlahnya mencapai ribuan eksemplar yang dapat dikelompokkan menjadi tiga, yaitu; (1) Ilmu Hisāb Haqiqi Taqrībi, (2) Ilmu Hisāb Haqiqi Tahqĩqi, (3) Ilmu Hisāb Kontemporer. Ironinya, hasil perhitungan hisāab dari tabel yang banyak jumlahnya itu, satu sama lain tidak sama persis. Ketiga, hambatan terletak pada perbedaan prinsip pakar Hisab dalam menetapkan ketinggian hilal atau waktu ijtima' (konjungsi) yang dipakai dasar untuk menetapkan awal bulan.

Perbedaan dalam menetapkan ketinggian hilal atau waktu ijtima' (konjungsi) melahirkan lima kelompok, yaitu: 
Pertama, Ahli Hisab yang memposisikan ilmunya sekedar pelengkap hukum syara'. Mereka berpendirian, sekalipun menurut hisab hilal pada malam ke-30 tinggi di atas ufuq, tetapi tidak bisa dilihat dengan mata telanjang, maka malam itu belum ditetapkan sebagai bulan baru dan harus mundur sehari (istikmal). Sebaliknya, apabila ada berita visibilitas hilal pada malam ke-30, sementara menurut pakar hisāb hal itu mustahil terjadi-karena masih di bawah ufuq atau di atasnya tetapi masih teramat kecil, misalnya kurang dari 1 derajat-, dalam hal ini ada dua pendapat ulama. Pertama, menolak berita itu. Pendapat ini dikemukakan mutaakhirin mazhab Syafi'i, antara lain: asSubki, Imam Ramli, Syarwani, Imam Qalyubi, dan lain-lain. Kedua, menerima pendapat itu, asalkan diberitakan orang adil. Pendapat ini dipelopori Ibn Qasim dan dipakai mayoritas fuqaha' empat mazhab. Alasannya, karena Nabi Muhammad Saw. setiap menerima berita visibilitas hilal tidak pernah melibatkan ilmu Hisab. Bahkan beliau menerima berita orang awam (baca: A'rabi) dan dijadikan dasar untuk menetapkan awal atau akhir Ramadhan. Kemungkinan, riwayat inilah yang dipedomani pemerintah Saudi Arabia dalam menetapkan awal Ramaḍan, Hari Raya, dan wuquf di Arafah. Bagi orang Indonesia yang merasa ahli Hisäb, sebaiknya memahami riwayat hadis ini, sehingga bila sewaktu-waktu pemerintah Arab Saudi Arabia menetapkan hari wuquf di Arafah tidak sesuai dengan kalkulasi hisāa nya, bisa berpedoman kepada riwayat hadis tersebut. Kalau dalam konteks ini ahli hisāb tersebut tetap ngotot berpedoman dengan kalkulasi data hisäa dan hatinya menolak ketetapan pemerintah Arab Saudi, maka dikawatirkan ibadah hajinya tidak sah.

Kedua, Ahli Hisab yang menggunakan kalkulasi ḩisäbnya untuk mengganti dasar ru'yat atau istikmal, tetapi masih mengaitkan dengan dasar rukyat tersebut. Karenanya,ia mensyaratkan hasil hisāb bisa menggantikan rukyat apabila menurut perhitungan hisäab, hilal berada di atas ufuq dan mungkin dirukyat, misalnya ketinggian 3 derajat.

Ketiga, Ahli Hisab yang menggunakan hisäbnya untuk mengganti rukyat dengan syarat hasil perhitungannya menunjukkan hilal berada di atas ufuq walaupun tidak mungkin dirukyat karena sangat rendah. Ahli hisāb ini sudah meninggalkan dasar rukyat istikmal berpindah ke dasar lain, yaitu dari dilihatnya hilal menjadi wujudnya hilal. Jadi, apabila saat matahari terbenam menurut hisäb sudah ada hilal—walaupun tidak 
mungkin dirukyat—malam itu sudah dikatagorikan bulan baru. Lebih lanjut, kata syahida pada Q.s. al-Baqarah (2): 185 mereka tafsirkan dengan aiqana, walaupun mayoritas mufassir memberi makna hadara (berada di rumah, tidak musafir).

Keempat, Ahli hisāb yang menggunakan ḥisäbnya untuk mengganti rukyat. Dengan syarat, hasil hisāb tersebut menunjukkan telah terjadi ijtima' (konjungsi) sebelum matahari terbenam. Walaupun—setelah matahari terbenam-di atas ufuq tidak ada hilal sama sekali. Ahli hisāb ini sudah meninggalkan dasar rukyat istikmal berpindah ke dasar lain, yaitu pendapat yang menyatakan bahwa ketentuan antara satu hari dengan hari berikutnya dibatasi dengan terbenamnya matahari. Dan perpindahan satu bulan dengan bulan berikutnya dibatasi dengan ijtima'. Kalau terjadi ijtima' sebelum matahari terbenam, maka setelahnya sudah masuk hari dan bulan baru. Mereka mendasarkan pendapatnya itu dengan ayat Q.s. Yasin (36):39.

Kelima, Ahli hisāb yang menggunakan hisābnya untuk mengganti rukyat. Dengan syarat, hasil kalkulasinya menunjukkan telah terjadi ijtima' sebelum terbit fajar. Ahli hisāa ini sudah meninggalkan dasar rukyat istikmal berpindah ke dasar lain, yaitu pendapat yang mengatakan, perpindahan satu bulan ke bulan berikutnya limitnya ijtima', dan puasa itu dimulai dari munculnya fajar. Sehingga kalau terjadi ijtima’ sebelum fajar, maka waktu fajar dan setelahnya telah masuk bulan baru, baik untuk puasa Ramadhan maupun hari Raya. Mereka mengaitkan pendapatnya dengan Q.s. al-Baqarah (2): 187.

Perbedaan ahli Hisab dari nomor satu sampai lima di atas merupakan hambatan besar untuk menyeragamkan prosedur mengawali 1 Syawal dan Dzulhijah dan menjadikan mathla' berlaku global (international).

\section{Teknik Pengamatan Hilal dan Gangguan yang Terjadi}

Teknik pengamatan hilal selain menggunakan cara konvensional, dapat dilakukan dengan alat bantu teleskop dan data penampakannya dapat direkam sesuai keinginan. Pada zaman dahulu (salaf), pengamatan hilal untuk menentukan 1 Ramaḍan atau Syawal dilakukan dengan cara ruyatyaitu melihat penampakan bulan baru di permukaan bumi dengan mata telanjang. Seiring dengan perkembangan ilmu pengetahuan dan 
teknologi, pengamatan hilal kini dilakukan menggunakan teleskop yang diyakini dapat membantu mempermudah melihat penampakan bulan (bilal) walaupun dalam keadaan berawan. Di samping itu, berdasarkan petunjuk dari Allah sesuai firmannya seperti yang tercantum dalam Q.s. Yunus ayat 5, penampakan bulan setiap saat dapat diperkirakan keberadaannya dengan menggunakan model perhitungan matematis falakiyah (hịisāb).

Pengamatan hilal di wilayah Indonesia relatif sulit apabila dibandingkan dengan negara lainnya, karena wilayah Indonesia merupakan negara maritim kontinental terdiri dari 1/6 daratan 2/6 lautan, dan 3/6 merupakan wilayah udara di mana proses fisis pembentukan awan berlangsung. Letaknya berada di equator, yang banyak menerima energi matahari sepanjang tahun dan potensial membangkitkan awan konvektif. Selain itu, negara Indonesia secara geologis, memiliki banyak gunung yang mentriger pembentukan awan orografis. Indonesia juga merupakan pertemuan dua sistem sirkulasi udara yaitu Utara-Selatan (hadley) karena posisinya berada di antara 2 benua Asia-Australia yang ditengarai dengan adanya persistant angin selama enam bulan dari Utara yang membawa berkah musim hujan dan berganti arah pada enam bulan berikutnya yang berlangsung musim kemarau, dan sirkulasi Timur-Barat (Halker) karena Indonesia berada di antara dua samudera Pasifik-Hindia. Terkadang, sirkulasi walker mendominasi wilayah Indonesia. Keadaan semacam ini akan memicu banyak hujan (La_Nina) dan sebaliknya terkadang memicu sedikit hujan atau kemarau panjang (El-Nino)

Berdasarkan kondisi geografis tersebut dan proses fisis dan dinamis yang menyertai, secara garis besar berdasarkan data klimatologi, Indonesia memiliki tiga (3) tipe iklim yaitu tipe iklim monsun yang ditengarai enam bulan relatif banyak hujan (Oktober-Maret) dan enam bulan berikut relative sedikit hujan (April-September), tipe iklim Equatorila banyak hujan sepanjang tahun curah hujan $(\mathrm{CH})$ maksimum, yang biasanya berlangsung pada bulan Maret dan Oktober, tipe iklim lokal yaitu kebalikan dari tipe iklim monsun. Manakala di daerah tipe iklim monsun musim hujan, di daerah tipe iklim local justru musim kemarau, demikian sebaliknya. Bahkan pada tahun-tahun tertentu (temporer), seluruh wilayah Indonesia terkadang mengalami musim hujan sepanjang tahun ( $\mathrm{La}-\mathrm{Nina})$. Atau 
sebaliknya, juga mengalami $\mathrm{CH}$ yang relatif kecil sepanjang tahun (El-Nino). Secara umum, di wilayah Indonesia dapat dikatakan banyak hujan sepajang tahun. Hal ini sekaligus menggambaran banyak awan atau kandungan uap air di udara relatif banyak, yang ditengarai menyebabkan kelembapan udara $(\mathrm{RH})$ relatif tinggi sepanjang tahun. Keadaan inilah yang menyulitkan pengamatan hilal di Indonesia. Kendati wilayah Indonesia relative sulit dilakukan pengamatan hilal, namun sebagai umat manusia diwajibkan untuk berikhtiar atau berupaya semaksimal mungkin untuk melakukan pengamatan (rujyat al-hilal) secara konvensional (mata telanjang), maupun menggunakan teleskop.

Hasil pengamatan hilal yang dilakukan pada tanggal 24 Juni 2017 pukul 17.43 di stasiun Geofisika Kupang berhasil diperoleh gambar bulan baru (new moon) 1 Syawal $1438 \mathrm{H}$. Namun penampakan bulan tersebut diragukan para ahli astronomis karena ukuran penampakan bulan lebih kecil dari teoritis dan penampakan tersebut dianggap sebagai derau (gangguan). Secara rinci uraian tersebut dimuat dalam Koran Kompas tanggal 7 Juli 2017. Untuk meyakinkan bahwa hasil pengamatan yang dilakukan para pengamat hilal di stasiun Geofisika Kupang tersebut benar adanya dan dilakukan sesuai SOP, perlu dikaji ulang secara teoritik berdasarkan tinjauan fisis-dinamis. Dengan kajian ulang semacam ini diharapkan semua pihak bisa memahami hasil pengamatan tersebut.

\section{Tinjauan Teoretis}

Secara garis besar, untuk menentukan bulan baru dapat dilakukan dengan dua cara yaitu hisāa dan rukyat. Sesuai syar'i pada jaman Rosul pengamatan ru'yat dilakukan di permukaan bumi secara alamiah dengan melihat penampakan bulan dengan mata telanjang. Namun seiring dengan perkembangan ilmu pengetahuan dan teknologi, kini pengamatan (ru'yat) dapat dilakukan dengan menggunakan alat bantu teleskop. Saat ini pengamatan penampakan bulan secara alamiah dengan mata telanjang muncul permasalahan karena udara semakin keruh akibat pembuangan gas-gas dari cerobong industri/pabrik, semakin banyaknya gas buang dari kendaraan roda empat (4) atau motor, gas buang dari ibu rumah tangga, industry, kebakaran hutan, atau kandungan uap air di udara banyak sekali di sepanjang medium sehingga penglihatan terganggu. 
Salah satu upaya untuk mengatasi pengamatan di permukaan bumi agar diperoleh hasil yang otentik, dapat dilakukan dengan bantuan alat teleskop yang datanya dapat direkam menggunakan komputer dan data tersebut hasilnya dapat dianalisis secara berulang-ulang dengan software aplikasi yang tersedia. Sedangkan penentuan bulan baru menggunakan model hisāb hanya dilandasi model matematisfalakiyah misalnya dengan menggunakan standar tertentu tinggi hilal. Selanjutnya apabila kriteria tersebut berdasarkan perhitungan, diyakini hasilnya sesuai kenyataan dengan pengamatan. Di samping itu, model hisāb ini juga dapat digunakan sebagai patokan untuk mengetahui daerah mana saja di permukaan bumi, di mana para pengamat dapat melihat bulan secara langsung dengan mata telanjang dan daerah mana saja yang dapat melihat penampakan bulan menggunakan alat bantu teleskop.

Landasan ilmiah digunakannya model hịsāb untuk melakukan hilal yaitu firman Allah dalam Al-Quran surat Yunus ayat 5 yaitu sebagai berikut:

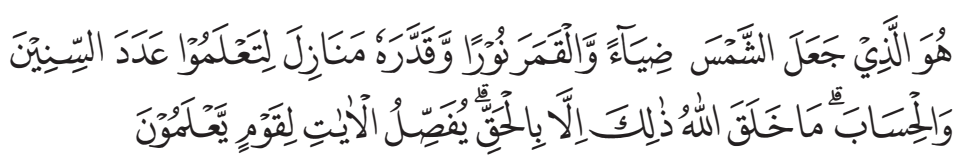

Dia-lah yang menjadikan matahari bersinar dan bulan bercahaya dan ditetapkan-Nya bagi bulan itu manzilah-manzilah, supaya kamu mengetahui bilangan tahun dan perhitungan (waktu). Allah tidak menciptakan yang demikian itu melainkan dengan hak. Dia menjelaskan tanda-tanda (kebesaran-Nya) kepada orang-orang yang mengetahui.

Salah satu faktor yang mendukung keberhasilan pengamatan hilal ditentukan keadaan cuaca saat itu, di antaranya: tingkat kecerahan atmosfer yang menggambarkan kecerahan atmosfer di sepanjang medium tersebut. Besarnya nilai kecerahan atmosfer dapat ditentukan dengan memperhatikan perbandingan besarnya radiasi di permukan bumi (global solar radiation) dan radiasi di puncak atmosfer (extra terrestrial solar radiation) sebagai fungsi kedudukan (deklinasi) matahari. Untuk mengetahui tingkat kecerahan atmosfer dapat dikonversikan menggunakan nilai transmisivitas yang harganya berkisar antara $0 \mathrm{~s} / \mathrm{d}$ 1. Semakin mendekati nilai satu (1) menunjukkan bahwa radiasi yang diterima di permukaan bumi relatif besar. Hal tersebut menggambarkan bahwa penjalaran radiasi matahari di sepanjang atmosfer sedikit 
terhalang uap air di udara (awan) atau polutan yang mengambang di atmosfer. Keadaan tersebut mengakibatkan atmosfer relatif cerah. Demikian sebaliknya, apabila nilai transmisivitas kecil, atmosfer gelap. Besarnya radiasi di permukaan bumi sesuai hukum Beer Bouger Lamber (K.N.Liau 2002:28) sebanding dengan besarnya radiasi di puncak atmosfer yang akan meluruh secara exponensial sebagai fungsi koeffsien penyerapan $\left(\mathrm{k}_{\alpha}\right)$ dikalikan kerapatan udara $(\tau)$ sepanjang medium dan jarak matahari terhadap bumi (ds). Model matematis Formula untuk menghitung radiasi dipermukaan bumi dinyatakan seperti persamaan berikut ini:

$$
\mathrm{hs}=\mathrm{ho}^{*} \exp \left(-\mathrm{k}_{\alpha}{ }^{*} \tau^{*} \mathrm{~d} s\right)
$$

Selanjutnya, besarnya nilai $\exp \left(-\mathrm{k}_{\alpha}{ }^{*} \tau^{*} \mathrm{~d} d\right)$ disebut koeffisien transmisivitas yang dapat digunakan sebagai acuan (patokan) untuk menentukan tinggkat kecerahan atmosfer. Dengan manipulasi matematis persamaan 1) dapat dituliskan sebagai berikut:

$$
\exp \left(-k \alpha * \tau^{*} d s\right)=\text { hs/ho }
$$

Sedangkan besarnya radiasi dipuncak atmosfer (ho), secara matematis dinyatakan sebagai berikut (Seyed Abbas Mousavi Maleki 2017:20):

ho $=24 / \Pi^{*} \mathrm{Io}^{*}\left(1+0.033^{*}\left(\cos \left(2 \Pi^{*} \mathrm{n} / 365.24\right)^{*} \cos (\theta)\right)^{*} \cos (\delta)^{*} \sin (\sin \mathrm{Ws}\right.$ -Ws*cosWS ...3)

Untuk menghitung ho diperlukan input data nilai panjang hari (Ws) dan deklinasi matahari ( $\delta$ ). Kemudian, untuk mengetahui nilai tersebut dapat dihitung menggunakan formula sebagai berikut:

$$
\begin{aligned}
& \text { Ws } \left.=\operatorname{arcos}\left(-\operatorname{tg} \theta^{*} \operatorname{tg} \delta\right) \ldots \ldots \ldots \ldots \ldots \ldots \ldots \ldots . . . . .4\right) \\
& \left.\delta=(23+27 / 60)^{*} \sin \left(360^{*} \mathrm{n} / 365.25\right) \ldots \ldots \ldots \ldots . .5\right)
\end{aligned}
$$

Di mana:

hs $=$ radiasi matahari di permukaan bumi

ho $=$ radiasi di puncak atmosfer

$\mathrm{k} \alpha=$ koeffisien penyerapan

$\tau \quad=$ kerapatan udara

$\mathrm{d} s=$ jarak bumi-matahari

$\delta \quad=$ deklinasi matahari

Ws = panjang hari 
Io $=$ Solar constan $(1353$ watt $/ \mathrm{m} 2)$

$\theta \quad=$ lintang stasiun

$\mathrm{n} \quad=$ hari ke $\mathrm{n}(\operatorname{tgl} 1$ Januari, $\mathrm{n}=1)$

$\mathrm{Hs} / \mathrm{ho}=$ koeffisien transmisivitas yang menyatakan tingkat kecerahan atmosfer

Di samping kecerahan atmosfer, perihal yang patut diperhatikan dalam pelaksanaan ru'yat al-hilal yaitu informasi prakiraan cuaca satu (1) atau dua (2) hari sebelum pengamatan dimulai dan pada saat pelaksanaan pengamatan. Informasi prakiraan cuaca tersebut harus diperbaiki (up date) setiap 1 jam sekali.

Salah satu tugas pokok BMKG bidang Pelayanan Meteorologi Publik yaitu dapat memberikan informasi prakiraan cuaca jangka pendek (Now casting) dengan rentang waktu hingga 2 jam ke depan (WMO No.485). Khusus informasi intensitas $\mathrm{CH}$ yang dipantau menggunakan radar atau satelit cuaca, tingkat akurasinya maksimum hingga 6 jam ke depan. Selanjutnya, dalam skala Mesoscale dalam kurun waktu 6-18 jam ke depan, prakiraan cuaca lebih akurat menggunakan model cuaca Numerik. Selanjutnya dalam skala synoptik pada kurun waktu 18-36 jam ke depan, lebih cocok menggunakan model Metoda out put statistik (Browning 980:161-184).

Salah satu tehnik prakiraan jangka pendek (2 jam ke depan) dapat digunakan dengan radar dan satelit (Gilberto A. Vicente dkk 1999). Dalam kajian ini menggunakan satelit Himawari Kanal IRI. Pengolahan data satelit Himawari dalam kajian ini menggunakan software GSLMPD, sedang penyajian gambar menggunakan software exel. Di samping itu, prakiraan jangka pendek juga dapat digunakan informasi radar cuaca yang tersebar di seluruh wilayah Indonesia sebanyak 40 unit ( $B M K G)$.

\section{Analisis dan Pembahasan}

Dengan menggunakan input data jumlah hari dalam setahun $(\mathrm{n}=1$ menyatakan tanggal 1 Januari) dapat diketahui posisi deklinasi matahari (ठ). Selanjutnya dengan menggunakan input bujur, dan lintang stasiun Kupang dapat diketahui radiasi dipuncak atmosfer dalam setahun. Perhitungan numerik deklinasi matahari dan radiasi di puncak atmosfer sepanjang tahun hasilnya disajikan seperti pada gambar 1 berikut ini. 

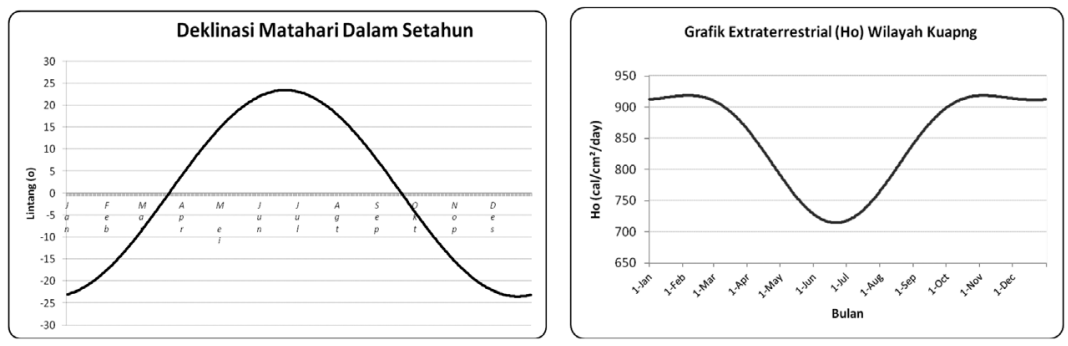

Gambar 1. Grafik Deklinasi matahari (kiri) dan Grafik Radiasi di Puncak Atmosfer Sepanjang tahun Wilayah Kupang (kanan)

Sesuai Hukum Beeer Bouger Lambert, besarnya radiasi matahari yang sampai di bumi baik radiasi di puncak atmosfer atau radiasi di permukaan bumi dipengaruhi faktor geometris yaitu posisi matahari terhadap posisi stasiun. Dari gambar tersebut terlihat bahwa pada saat deklinasi Matahari berada pada posisi terjauh dari equator (Juni-Juli), radiasi di puncak atmosfer di kota Kupang berada pada harga minimum. Sedangkan pada saat matahari di sebelah Selatan Equator (Januari-Desember) harganya maksimum. Berdasarkan data-data tersebut, pengamatan radiasi di permukaan bumi di stasiun Klimatologi Kupang (demikian juga untuk tempat yang lain) sangat bermanfaat untuk mendukung kegiatan pengamatan hilal. Pengamatan hilal yang diprakarsai BMKG dilakukan dua kali, yaitu: pertama, untuk menentukan awal bulan Ramadhan dan awal bulan Syawal. Berdasarkan perhitungan astronomis (hisāb) awal dan akhir Ramadhan 1438 H diprakirakan bertepatan dengan tanggal 25 Mei dan 24 Juni 2017.

Instansi pemerintahan di luar BMKG yang melakukan pengamatan hilal untuk menentukan awal bulan Ramadhan adalah LAPAN. Lokasi pengamatan yang dipilih LAPAN, di Tanjung Lesung, Propinsi Banten, Sedang BMKG, salah satunya di kota Kupang. Untuk mengetahui kinerja hasil pengamatan dari dua instansi tersebut, hasilnya disandingkan. Setelah hasilnya disandingkan, diperoleh penampakan hilal yang relatif sama (lihat gambar 3). Hal ini memberi pemahaman bahwa kinerja ke dua instansi tersebut dalam klasifikasi katagori baik. 

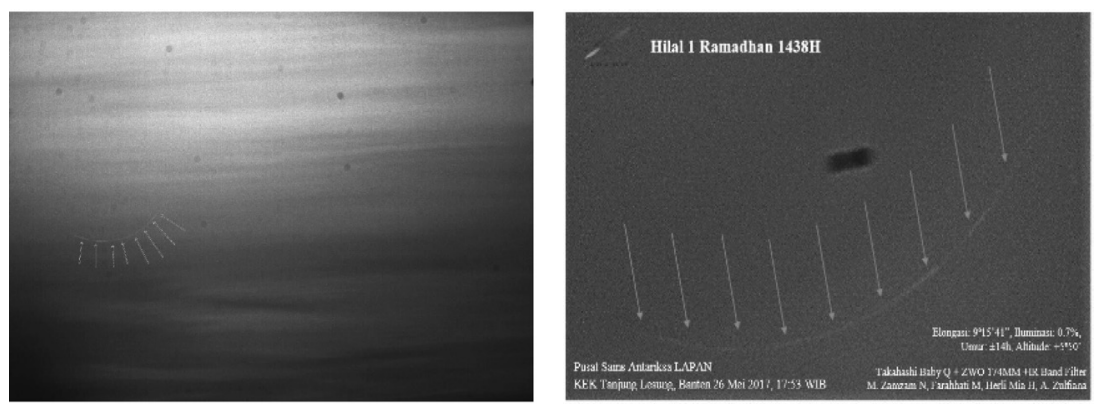

Gambar 3. Hasil pengamatan hilal pada tanggal 25 Mei 2017 yang dilakukan BMKG di Kupang NTT (kiri) dan LAPAN di Tanjung Lesung, Banten (kanan)

Pengamatan hilal untuk mengetahui awal bulan Syawal 1438H, BMKG melakukan pengamatan serentak di 17 lokasi pengamatan di seluruh wilayah Indonesia. Berdasarkan laporan, semuanya tidak diperoleh hasil seperti yang diharapkan, karena cuaca pada tanggal 24 Juni 2017 pada pukul 17.00-18.00 di seluruh wilayah Indonesia umumnya kandungan uap air (awan di udara) relatif banyak, bahkan di wilayah Indonesia bagian Barat ditengarai terdapat awan Cumulunimbus $(\mathrm{Cb})$.

Kondisi cuaca di Indonesia pada bulan Juni 2017 cukup istimewa karena biasanya berlangsung musim kemarau, namun kenyataannya, pada akhir Juni masih banyak awan dan hujan. Keadaan tersebut berlangsung sampai pertengahan bulan Juli 2017. Lazimnya pada bulan Juni kondisi cuaca didominasi sirkulasi udara kering (monsun) dari Australia yang ditengarai sedikit awan, $\mathrm{RH}$ relatif rendah $(<65$ $\%$ ), dan radiasi matahari cukup tinggi. Namun dalam kenyataannya, pada bulan Juni 2017, kondisi atmosfer di wilayah Indonesia umumnya masih banyak awan. Diduga, akibat pengaruh MJO dan monsun Asia (gambar 4 kanan) masih mendominasi wilayah Indonesia. Karena begitu luas wilayah Indonesia, kondisi geografis (tropis, gunung, hutan, laut), sistem sirkulasi yang komplek (Hadley/ monsun, walker, darat-laut/lokal) di wilayah Indonesia, cukup sulit untuk membuat prakiraan jangka panjang. Karenanya, cukup sulit untuk mengidentifikasi fenomena cuaca yang dominan di suatu wilayah (Madden-Julian 2017).

Untuk mengetahui kondisi cuaca pada saat pelaksanaan hilal di 
wilayah Indonesia, berikut disajikan analisis tinggi dasar awan hasil olahan satelit Himawari kanal IR3 menggunakan model lapserate (Donal Ahrens 2011:180).
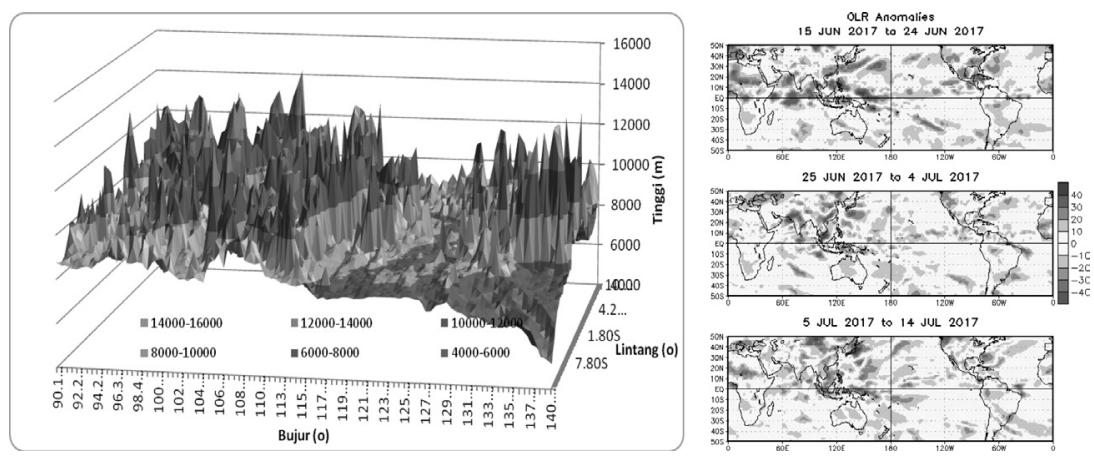

Gambar 4. Prakiraan Tinggi Penampakan awan (m) di wilayah Indonesia tanggal 24-06-2017 pukul 10.46 UTC (kiri) dan Evaluasi dan Prakiraan cuaca menggunakan analisis MJO (Juni-Juli 2017)

Kendati kondisi atmosfer tanggal 24 Juni 2017 diliputi banyak awan, namun dalam sekejab (sekitar pukul 17.43) pengamatan di Kupang, diperoleh penampakan bulan meskipun sangat tipis sekali. Hasil jerih payah pengamatan yang dilakukan petugas BMKG di Kupang diragukan ahli astronomi karena ukurannya yang lebih kecil yaitu $67 \%$ dari nilai idealnya dan penampakan posisinya tidak tepat berada di tengah kamera pengamatan. Ukuran penampakan yang dihasilkan lebih kecil $33 \%$. Patut diduga akibat pengaruh kandungan uap air di sepanjang medium pengamatan dan berfungsi sebagai lensa cekung. Sedang posisi penampakan tidak di tengah karena saat membidik kamera kurang bergeser ke kanan. Hal ini dilakukan para pengamat akibat terpaku perhitungan hisāb di mana posisi azimuth bulan yaitu $290^{\circ} 32^{\prime} 45^{\prime \prime}$, sekalipun kenyataannya dalam observasi harganya lebih besar.

Sebagai pembanding hasil yang serupa juga dihasilkan dari pengamatan penampakan hilal yang dilakukan pemerintah Arab Saudi. Hasilnya juga tidak tepat berada di tengah kamera. Untuk lebih jelasnya dapat dilihat hasil pengamatan ke dua pemerintahan Indonesia dan Arab Saudi seperti yang disajikan pada gambar 4 . 

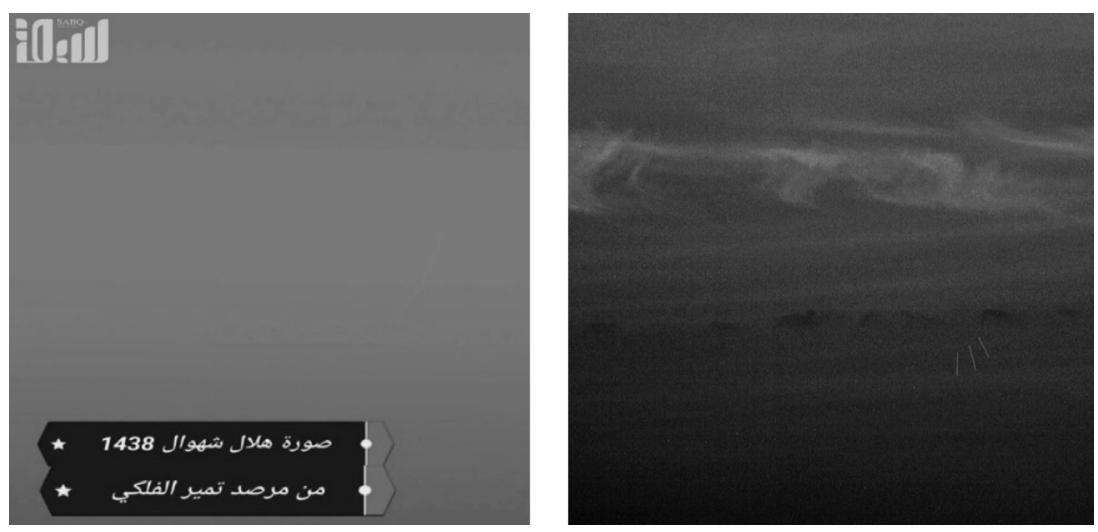

Gampar 4. Hasil pengamatan di Kupang dan Di Arab Saudi tanggal 24 Juni 2017.

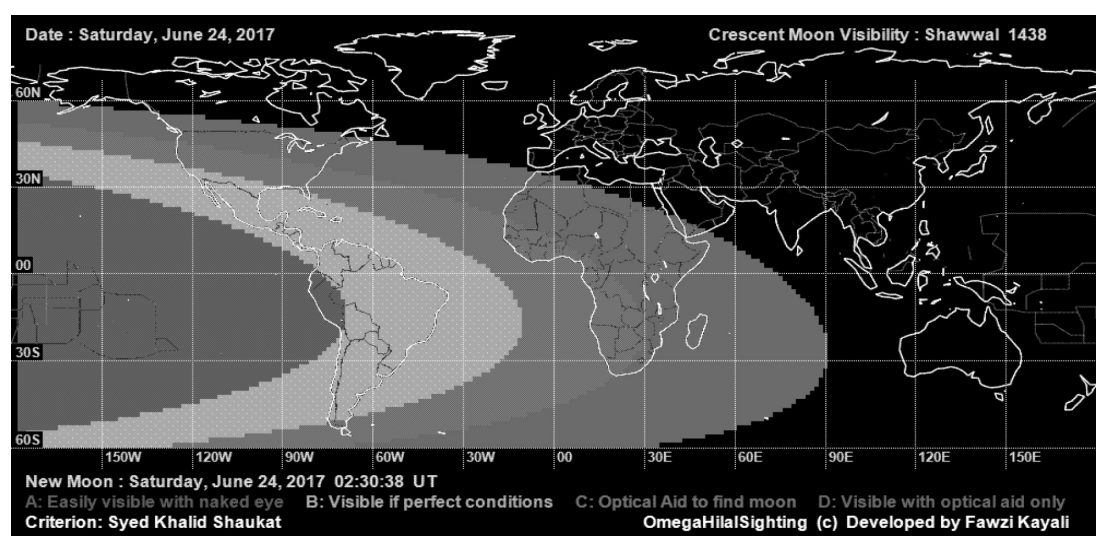

Gambar 5. Prakiraan Wilayah Rukyat di seluruh dunia berdasarkan Perhitungan Hisāb Falakiyah

Dari gambar tersebut tampaknya petugas rukyat harus di perbanyak yaitu dengan meningkatkan kerjasama kementrian (Lembaga) dalam hal ini dengan Kementrian Luar Negeri. Apabila kerjasama tersebut terwujud, Duta Besar Indonesia yang berada di wilayah Amerika (Latin) diberi tugas tambahan bekerjasama dengan kaum muslimin di wilayah tersebut untuk melakukan pengamatan hilal secara langsung (mata telanjang) dan beritanya diinfokan secara on line (langsung) via WA. Mudah-mudahan dengan gagasan ini, apa yang disabdakan Rosul Muhammad Saw. dapat diwujudkan sebagaimana awal mula kejadian tentang pengamatan hilal ini. 
Sebagaimana di jelaskan di atas bahwa pelaksanaan rukyat di wilayah Indonesia relative sulit sepanjang tahun karena atmosfer wilayah Indonesia banyak kandungan uap air /awan/hujan Untuk meminimalisir pengaruh uap air di udara, kemampuan manusia tidak mungkin dapat dilakukan, namun kendala tersebut dapat disiasati dengan melakukan rukyat al-hilal menggunakan pesawat yang terbang di atas pertumbuhan awan. Selanjutnya hasilnya dibandingkan dengan hasil pengamatan di permukaan (lihat gambar 5). Kegiatan pengamatan menggunakan pesawat terbang, selain untuk menghindari uap air juga dimaksudkan untuk menguji ketelitian hasil perhitungan menggunakan model hịsāb.

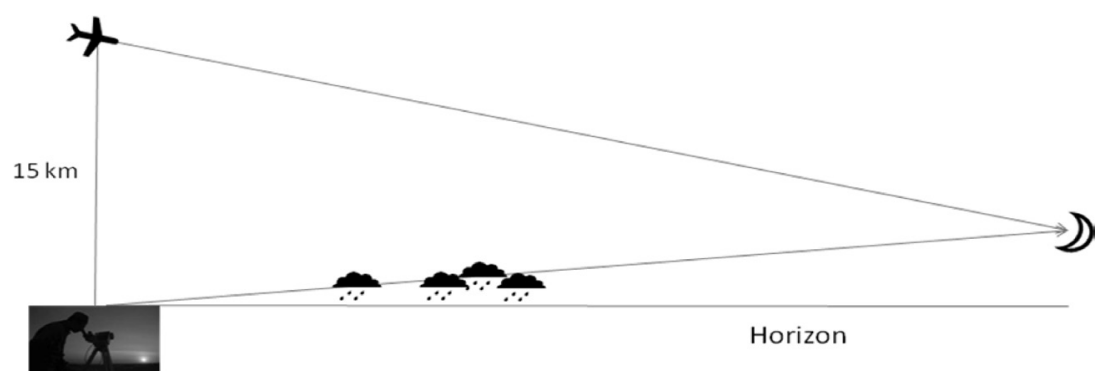

Gambar 5. Tehnik pengamatan hilal menggunakan sarana pesawat terbang

\section{Penutup}

Berdasarkan analisis dan pembahasan tersebut di atas, hasil pengamatan hilal menggunakan model rukyat yang dilakukan pegawai stasiun geofisika Kupang dapat disimpulkan sebagai berikut:

Pertama, kondisi meteorologi dan astronomis saat pelaksanaan hilal tahun 2017 sangat istimewa, karena wilayah Indonesia pada akhir bulan Juni umumnya berlangsung musim kemarau, namun tahun 2017 ditengarai banyak kandungan uap air/awan /hujan keadaan tersebut justru semakin mempersulit pelaksanaan rukyat. Disamping itu posisi bulan dan Matahari pada tanggal 24 Juni berada pada titik terjauh dari kota Kupang keadaan tersebut secara teoritis mempengaruhi penglihatan terhadap penampakan bulan.

Kedua, hasil pengamatan hilal dengan model rukyat menggunakan teropong Vixen ED81S dan detektor Canon 500D yang dilakukan stasiun Geofisika Kupang hasilnya menyerupai dengan hasil pengamatan oleh Astronomical Obsevatory in Tumair, Saudi Arabia 
yaitu Posisi tidak berada di ditengah, ukuran hasil pemotretan sama besarnya, hal ini memberikan makna bahwa hasil pengamatan yang dilakukan BMKG datanya tidak perlu diragukan.

Ketiga, untuk menghimpun data pengamatan hilal dengan metode rukyat hendaknya dilakukan kerjasama internasional dengan melibatkan staf kedutaan luar negeri di berbagai Negara. Karena berdasar perhitungan hisāb wilayah yang di prakirakan dapat melihat hilal secara langsung dengan mata telanjang wilayahnya dapat diketahui secara rinci, hanya tergantung keadaan cuaca saat itu ditempat tersebut.

Keempat, berdasarkan sabda Rosulullah siapa saja yang telah melihat hilal di permukaan bumi yang dilakukan dengan benar dan memenuhi syarat syar'i semua pihak untuk mengikuti. Umat Islam hendaknya mengutamakan ukhuwah islamiyah katimbang mengedepankan kekuasaan politik dan system kewilayahan (matla).[]

\section{Pustaka Acuan \\ Buku}

Ahrens, Donal, Peter L Jackson, Christine E.J. Jackson Meteorology Today. An Introduction to weather, Climate, and Environtment, 2011.

Al-Bukhari, Muhammad bin Isma'il, Al-Jami' Al-Shahih, Beirut: Dar Ibn Kasir al Yamamah, 1987.

Al-Nisabury, Muslim bin Hajjaj, Shahih Muslim, (Beirut: Dar Ihya' At-Turas Al'Araby, tth.

Al-Nisabury, Muhammad Bin 'Abdullah Al-Hakim, Al-Mustadraq 'Ala AsShahihaini, Beirut: Dar Al-Kutub Al-'Ilmiyah, 1990.

Browning, K. A. Meteorological Magazine, Vol.108, (1979).

Liau, K.N. An Introduction To Solar Aradiation, Second edition, tp: 2002.

Majelis Ulama Indonesia, Fatwa Majlis Ulama Indonesia (MUI) dalam Perspektif Hukum dan Perundang-Undangan.

Madden-Julian, Oscillation: Recent Evolution, Current Status and Predictions. Update prepared by: Climate Prediction Center / NCEP. 17 July 2017. http://www. cpc.ncep.noaa.gov/products/precip/CWlink/ghazards/index.php.

Maleki, Seyed Abbas Mousavi, H. Hizam and Chandima Gomes 1, Review Estimation of Hourly, Daily and Monthly Global Solar Radiation on Inclined Surfaces: Models Re-Visited, 2017.

Raharto, Moedji, Awal Shaum Ramadhan 1418 H Mengapa Diharapkan Bertepatan dengan Akhir Tahun 1997? Republika, 23/12/1997.

Sunanto, Musyrifah, Sejarah Kebudayaan Islam, Jakarta: Perkasa, 1991 
Sholeh, Moh. Rodhi, Rukyatul Hilal, Jakarta: Pustaka Annizomiyah, 1992

Thohari, Fuad, Kajian Fatwa MUI Tentang Penentuan Awal Ramadhan, Syawal, Dan Dzul Hijjah; Upaya Rekonstruksi Metodologis, Jakarta: Badan Litbang dan Diklat Kemenag RI, 2012.

Vicente, Gilberto A. , Roderick A. Scofield and W. Paul Menzel. Bulletin of the American Meteorological Society, Vol. 79, No. 9, September 1999.

Wheeler, Matthew C. Wheeler And Harry H. Hendon (2004). An All-Season Real-Time Multivariate MJO Index: Development of an Index for Monitoring and Prediction.

\section{Sumber Online}

Https://www.moonsighting.com/1438shw.html.

http://pussainsa.lapan.go.id/index.php/subblog/read/2017/547/PengamatanHilal-Ramadhan-1438-H

Fuad Thohari, Achmad Sasmito, Andy ES, Jaya Murjaya, Rony Kurniawan, Fakultas Syariah dan Hukum UIN Syarif Hidayatullah Jakarta, Jl. Ir. H. Juanda 95 Ciputat, Jakarta Selatan, E-mail: fuadinfoulama@yahoo.com 
AHKAM Jurnal Ilmu Syariah (ISSN: 1412-4734/E-ISSN: 2407-8646) is a periodical scientific journal published by Faculty of Sharia and Law of Syarif Hidayatullah State Islamic University Jakarta in collaboration with Indonesian Scientist and Sharia Scholar Association (HISSI). This journal specifically examines the science of sharia and obtains to present various results of current and eminence scientific research. The administrators receive articles as contributions Sharia and Islamic law disciplines from scientists, scholars, professionals, and researchers to be published and disseminated. The article will be situated in a selection mechanism, a review of proved reders, and a strict editing process. All articles published in this Journal are based on the views of the authors, but they do not represent the authors' journals or affiliated institutions.

AHKAM has been accredited based on the determination of Director General of Research Reinforcement and Development, Research, and Technology Ministry of Higher Education of Republic of Indonesia, No. 36/a/E/KPT/2016 (valid until 2021). 